\title{
Biotechnology and the built environment
}

Advances in the biological sciences have, we are told, brought about a biotechnology revolution. Architecture has a long-standing relationship with both biophilia, finding inspirations in natural forms and structures, and biomimicry, imagining nature in terms of biological systems to inspire design. A revolution in biotechnology may, however, precipitate a more direct relationship between biology and the built environment, where architecture makes use of materials and structures that are, in part, living. This special issue of arq, curated by Martyn Dade-Robertson and Rachel Armstrong, examines the potential of biotechnology to inform architectural design. It addresses a deeper engagement with biotechnology as a material and construction method, examining how nature is being imagined as a technology. It includes theoretical and practical perspectives addressing a range of philosophies and approaches.

Dade-Robertson and Armstrong provide contrasting but intersecting papers.

Dade-Robertson's 'perspective' (pp. $5^{-8}$ ) argues for a shift in our understanding of 'building science', engaging architectural research in more fundamental science and engineering led by speculation and informed by emerging scientific fields such as synthetic biology. Armstrong (pp. 29-38) reflects on how synthetic biology might inform design paradigms that challenge conceptions of engineering and scientific insight in an age of living matter.

Contributors to this arq come from a broad field of disciplines and approaches to the design of bioreceptive materials. EcoLogic Studio consider the use of slime mould as a bio-computational design tool (pp. 51-64). AStudio offer an ecological approach to the built environment through the application of microorganisms such as algae (pp. 10-19). Authors from ARUP discuss the use of photobioreactors in their pioneering BIQ house (pp. 73-79). Additionally, Marin Sawa provides an auto-ethnography as a designer working within a biological laboratory setting as part of a long-term collaboration (pp. 65-71). Andrew Ballantyne takes a broader philosophical perspective that stands against the unitary thinking which underpins modern design paradigms (pp. 39-44). Experimental anatomist Jamie Davies, meanwhile, contrasts design and construction in biological systems with the current prevailing conception of design architecture (pp. 45-50).

An ecology of thinking emerges from these articles which offers exciting opportunities for architectural design research and embodies the possibilities of biotechnology - not only to provide material and technology to construct new design experiences but also to change the way that we see, and therefore relate to, the natural and built environments.

THE EDITORS 


\section{architectural research quarterly}

\section{Subscribe now for 2016}

Innovative in conception, unique in breadth and generously illustrated, this pace-setting quarterly publication from Cambridge University Press links, on a global scale, the worlds of architectural practice and research. arq regularly includes extensive peer-reviewed sections on design, history, theory, construction, environmental design, education and practice - as well as structures, urbanism and documents. These are supplemented by letters, reports, reviews and an annual index. Each issue opens with a leader and closes with insight, a personal end-piece. In its eighteen year history, arq has published work from all over the world: from Chile to Sweden and from Japan to the Netherlands - with a strong representation from the United Kingdom and United States. arq, like architecture itself, is all-embracing and written by and for both practitioners and academics. It provides an outlet for all those who wish to disseminate their work to an international audience.
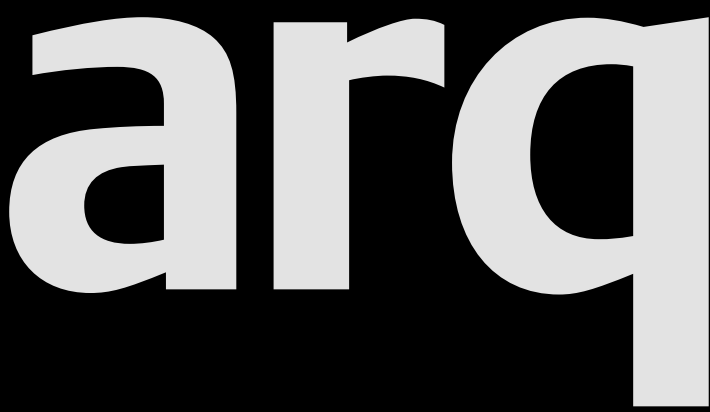

Please enter my subscription to

arq: architectural research quarterly, volume 20, 2016

$£_{297 / \$ 499 \text { institutions print and electronic }}$
$E_{36} 6 / \$ 60$ students print only
$E_{53} / \$ 81$ individuals print only

EU residents only. VAT may be payable at your local rate if not registered.

Ourvat registration number: Gв 214141614 If registered, your VAT registration no:

Total subscription payment $£ / \$$

Eu residents only, if not registered add VAT at appropriate rate

Canadian residents, add 7\% GST \$

Total $\mathbf{E} / \mathbf{S}$

Name

Address

\section{Payment enclosed}

Cheque in sterling or US dollars

(payable to Cambridge University Press)

| Credit Card - VISA | MasterCard | American Express (delete where applicable)

Card no

Expiry date

Signature

Photocopy this page and send your order to: Journals Customer Services, Cambridge University Press, UPH, Shaftesbury Road, Cambridge, CB2 8BS, UK

$T+44(0) 1223326070$

F +44 (o) 1223315052

E journals@cambridge.org

or in USA, Canada and Mexico send to:

Cambridge University Press, 1 Liberty Plaza,

Floor 20, New York, NY 10006, USA

T (914) 9379600

F (914) 9374712

E journals_subscriptions@cup.org 